\title{
A microstructural study of surface hydration on a magnesia refractory
}

\author{
Mucahit Sutcu ${ }^{\mathrm{a}, 1}$, Sedat Akkurt ${ }^{\mathrm{a}, *}$, Salih Okur ${ }^{\mathrm{b}, 2}$ \\ ${ }^{a}$ Mechanical Engineering Department, Izmir Institute of Technology, 35430 Izmir, Turkey \\ ${ }^{\mathrm{b}}$ Physics Department, Izmir Institute of Technology, 35430 Izmir, Turkey
}

Received 30 April 2009; received in revised form 15 January 2010; accepted 19 February 2010

Available online 25 March 2010

\begin{abstract}
Hydration of the surface of a periclase refractory was studied in a controlled humidity atmosphere ( $92 \%$ relative humidity) at $26^{\circ} \mathrm{C}$ for up to $92 \mathrm{~h}$. The effect of humidity on the specimens was examined using a scanning probe microscope (SPM) and a scanning electron microscope (SEM), which showed that the degree of hydration was noticeably less in the intergranular bond phase compared to the periclase crystallites. The SPM study indicated significant growth of hydrates on the refractory grain surface. Growth rate of the hydrate layer was least on $(001)$ orientation,

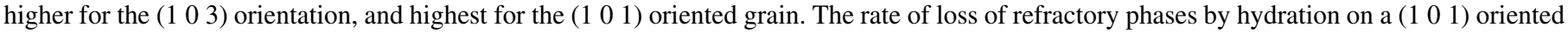
grain was $4.53 \mathrm{~nm} / \mathrm{h}$. This material loss may be insignificant for a bulk brick, but is a serious threat for a magnesia castable consisting of fine magnesia powder due to large surface area exposed to humidity or water itself.
\end{abstract}

(C) 2010 Elsevier Ltd and Techna Group S.r.l. All rights reserved.

Keywords: B. Surfaces; D. MgO; E. Refractories; Hydration

\section{Introduction}

Magnesia $(\mathrm{MgO})$ or the mineral form periclase is one of the most important refractory materials primarily because of its use in steelmaking. Periclase has a melting point over $2800{ }^{\circ} \mathrm{C}$, along with high temperature thermodynamic stability, which makes it a good candidate as a raw refractory material [1-3]. It is also available in relatively high purity in tonnage quantities at a low price. Like calcia, it suffers from hydration upon storage in moist environments, but to a much less extent [4]. This problem has seriously limited the refractory use of lime, which would otherwise be a very good refractory material. If the microstructure of a polycrystalline periclase grain is examined using the reflected light optical microscope, crystallites of periclase will be observed as randomly distributed equiaxed grains. If the same observation is repeated after a period of time, hydration of the surface during storage will be evident. It has been noted that different crystallites of $\mathrm{MgO}$ hydrate at different rates [5-7]. Moisture in the air reacts with $\mathrm{MgO}$ to

\footnotetext{
* Corresponding author. Tel.: +90 232750 6705; fax: +90 2327506701 .

E-mail addresses: mucahitsutcu@iyte.edu.tr (M. Sutcu),

sedatakkurt@iyte.edu.tr (S. Akkurt), salihokur@iyte.edu.tr (S. Okur).

${ }^{1}$ Tel.: +90 232750 6789; fax: +90 2327506701 .

${ }^{2}$ Tel: +90 232750 7706; fax: +90 2327507707 .
}

form $\operatorname{Mg}(\mathrm{OH})_{2}$, which forms a film layer on the surface of the refractory. This layer has a low refractoriness and easily dissociates upon exposure of the refractory to high temperatures or mechanical abrasion. Periclase refractories contain impurities like $\mathrm{Ca}, \mathrm{Si}$ and $\mathrm{Fe}$; which tend to segregate at grain boundaries [2,8]. Phases $\mathrm{MgO}$ can form include forsterite $\left(2 \mathrm{MgO} \cdot \mathrm{SiO}_{2}\right)$, merwinite $\left(3 \mathrm{CaO} \cdot \mathrm{MgO} \cdot 2 \mathrm{SiO}_{2}\right)$, monticellite $\left(\mathrm{CaO} \cdot \mathrm{MgO} \cdot \mathrm{SiO}_{2}\right)$, dicalcium silicate $\left(2 \mathrm{CaO} \cdot \mathrm{SiO}_{2}\right)$ and tricalcium silicate $\left(3 \mathrm{CaO} \cdot \mathrm{SiO}_{2}\right)$; depending on the $\mathrm{CaO} / \mathrm{SiO}_{2}$ ratio of the grain boundary phase $[2,8-10]$. Phases containing iron like $\mathrm{MgO} \cdot \mathrm{Fe}_{2} \mathrm{O}_{3}$ and $2 \mathrm{CaO} \cdot \mathrm{Fe}_{2} \mathrm{O}_{3}$ are less frequently observed. Iron generally goes into solid solution with magnesium containing phases [9]. However, a major portion of the surface area of the refractory exposed to humidity is $\mathrm{MgO}$, which comprises greater than $90 \%$ of the exposed surface material. In a previous study by Sutcu et al., the effect of crystallographic orientation of the individual grains was studied using scanning probe microscope (SPM) and scanning electron microscope (SEM) [7]. Those crystallites oriented along ( $\left.\begin{array}{lll}1 & 1 & 1\end{array}\right)$ were found to be the most vulnerable to hydration. A microstructural study of the hydration behavior of the grain boundary phases and magnesia grains of a polycrystalline magnesia refractory has not been reported in the literature. Research has been conducted on single crystal samples [5-7,11,12], while polycrystalline refractory samples were not studied. Salomao et al. studied 
the hydration of magnesia in powder form in a castable refractory; evaluating changes in strength, porosity, volume expansion and the drying rate of the bulk of the refractory castable product [13]. While this study did not address microstructural issues regarding hydration of magnesia, it contributed to the understanding of the bulk behavior of a castable made of fine powdered magnesia in contact with water. Large areas of magnesia were exposed to $\mathrm{H}_{2} \mathrm{O}$.

In a previous study by the authors [7], the hydration behavior of $\mathrm{MgO}$ single crystals was investigated. In this study, a commercial polycrystalline $\mathrm{MgO}$ refractory specimen was studied under similar humid conditions to understand how intergranular bond phases and randomly oriented $\mathrm{MgO}$ grains behave in a fired refractory sample. Images obtained from SEM are compared to those of SPM to observe how hydration progressed with time in a humid environment.

\section{Experimental procedure}

A sample $(4 \mathrm{~mm} \times 8 \mathrm{~mm} \times 8 \mathrm{~mm})$ from the interior of a commercial sized periclase (magnesia) refractory brick (Kumas, Turkey) was prepared by cutting it with a diamond disc saw. The brick's chemical composition is given in Table 1. A cut surface of the sample was mechanically polished dry using SiC grinding papers and polishing cloths with oil based diamond suspension and $0.05 \mu \mathrm{m}$ alumina suspension to a mirror finish. Microstructure was observed in a reflected light optical microscope (Nikon L150), then the surface morphologies were examined using a scanning probe microscope (Solver Pro from NT-MDT, SPM) and scanning electron microscope (Philips XL-30SFEG, SEM). The DIC (Differential Interference Contrast) mode of the optical microscope was used to observe surface relief on the polished sample. Another SEM was used to measure grain orientation by Electron Backscatter Diffraction (EBSD) analysis (Zeiss Supra 50VP-Oxford Instruments). Polished surface were exposed to hydration in a humidity chamber with a $92 \%$ relative humidity (RH) at ambient temperature of $26{ }^{\circ} \mathrm{C}$ for up to $92 \mathrm{~h}$. After exposure, the hydrated sample's polished surface was evaluated using both SPM and SEM. A grain intersection area which formed a triple grain junction on the sample was scanned in SPM on a $15 \mu \mathrm{m} \times 15 \mu \mathrm{m}$ surface area using semi-contact mode. In this imaging mode the cantilever probe is given an up and down tapping motion over the surface of the sample to obtain the surface profile. Hence surface height variations were measured. The sample surface roughness measurements were performed by a program module for processing and analysis of SPM images and SPM data (Image Analysis 2.2.0, NT-MDT). The same hydrated sample and its triple grain junction was then investigated by SEM.

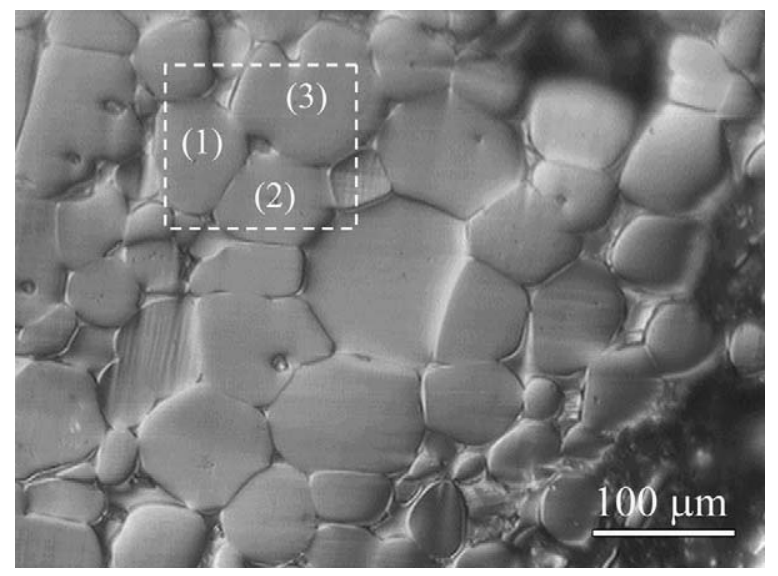

Fig. 1. Reflected light optical microscope DIC (Differential Interference Contrast) image $(200 \times)$ of polished periclase refractory specimen (marked region evaluated by SPM and SEM) before exposure to the controlled humidity atmosphere at $26^{\circ} \mathrm{C}$.

\section{Results and discussion}

An optical microscope image of the polycrystalline periclase specimen before humidity exposure is shown in Fig. 1. The largest magnesia grain sizes found in the sample were around $100 \mu \mathrm{m}$. The intergranular bond phase along the grain boundaries of magnesia was a glassy monticellite $\left(\mathrm{CaO} \cdot \mathrm{MgO} \cdot \mathrm{SiO}_{2}\right)$ with a hardness less than magnesia $[8,14]$. The area evaluated using SPM and SEM analysis is marked by a square in Fig. 1. Fig. 2 shows the EBSD (Electron Backscatter Diffraction) measurement result for this area in Fig. 1. The orientations of the three grains in this area were determined to

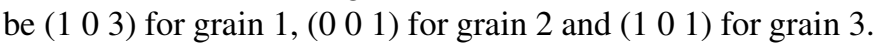

The three magnesia crystallites shown in Fig. 1 were unequally affected by humidity in the air at $26^{\circ} \mathrm{C}$. Fig. 3 shows three-dimensional SPM images of the region marked by a square in Figs. 1 and 2 at different exposure times to the $92 \%$ $\mathrm{RH}$ at $26{ }^{\circ} \mathrm{C}$. The physical effect of exposure time and humidity is clearly observed, with surface changes occurring because of the formation of magnesium hydroxide clusters, which increased with increasing exposure time. The initial as-polished surface was quite clean, as can be seen from Fig. 3a. After $1 \mathrm{~h}$ exposure at $92 \%$ relative humidity $(\mathrm{RH})$, hydrate clusters on the grains began to form (Fig. 3b). It is of interest to note that the intergranular bond phase of monticellite was less affected by humidity compared to the periclase grains. After $92 \mathrm{~h}$ of exposure at $92 \% \mathrm{RH}$ at $26^{\circ} \mathrm{C}$, the surfaces of the hydrated grains were extensively covered by a hydrate layer (Fig. 3c). The visible "hole" in the middle of the triple grain junction

Table 1

Published average chemical composition of the periclase grains.

\begin{tabular}{|c|c|c|c|c|c|c|c|}
\hline \multicolumn{6}{|c|}{ Chemical composition (wt\%) } & \multirow[t]{2}{*}{ Bulk density $\left(\mathrm{g} / \mathrm{cm}^{3}\right)$} & \multirow[t]{2}{*}{ Periclase crystallite size $(\mu \mathrm{m})$} \\
\hline $\mathrm{MgO}$ & $\mathrm{SiO}_{2}$ & $\mathrm{CaO}$ & $\mathrm{Fe}_{2} \mathrm{O}_{3}$ & $\mathrm{Al}_{2} \mathrm{O}_{3}$ & LOI & & \\
\hline 96 & $1.00-1.25$ & $1.80-2.20$ & 0.50 & 0.10 & 0.20 & 3.40 & $60-80$ \\
\hline
\end{tabular}



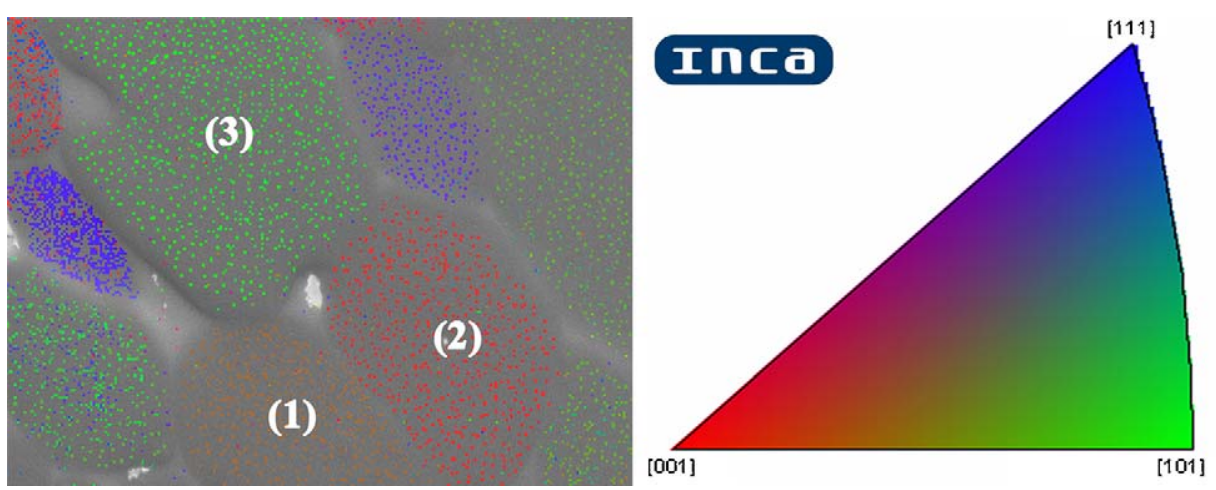

Fig. 2. The EBSD (Electron Backscatter Diffraction) image of the region that is marked by a square in Fig. 1.

(Fig. 3a-c) could be a pull-out that occurred during polishing or a preexisting pore.

Average surface roughness values for each grain; indicated by points 1, 2 and 3 in Figs. 2 and 3 for the different exposure

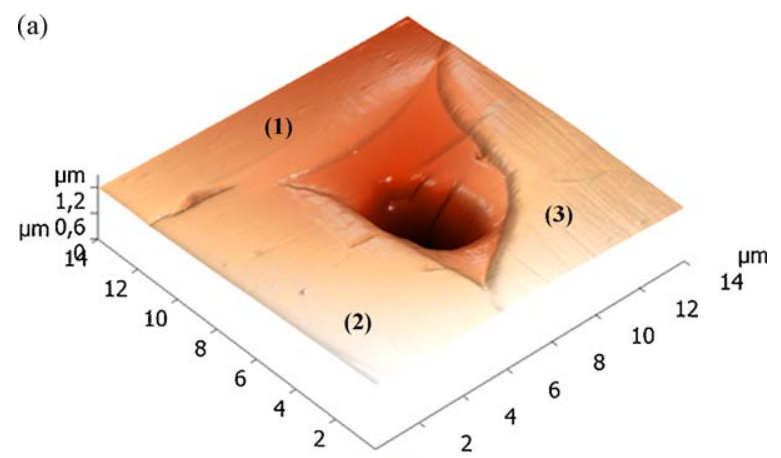

(b)

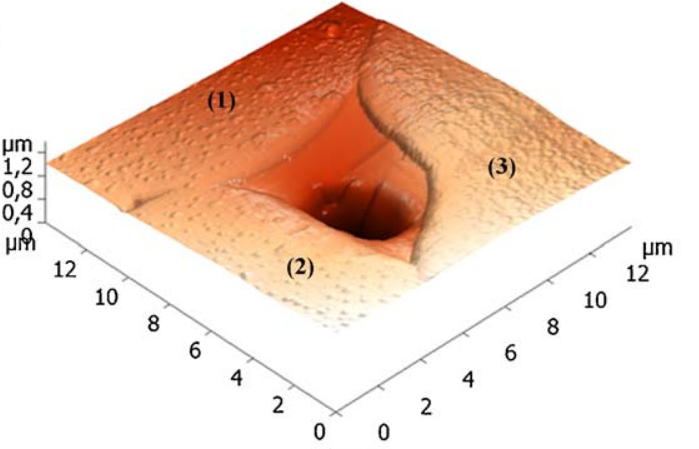

(c)

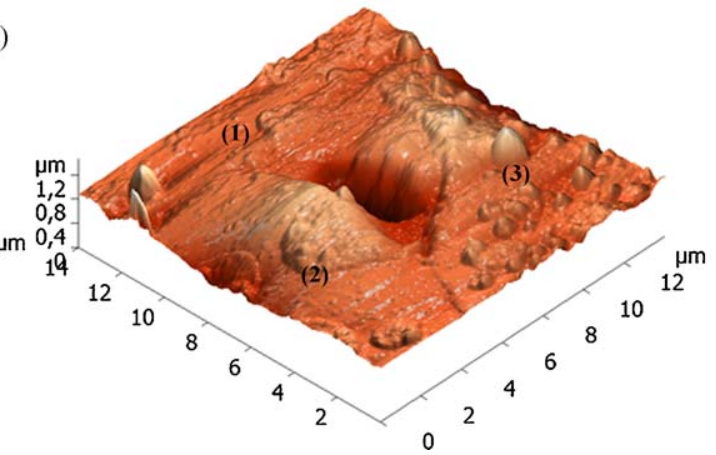

Fig. 3. 3D SPM images of the region marked by a square in Fig. 1 used to evaluate different exposure times at $92 \% \mathrm{RH}$ and $26^{\circ} \mathrm{C}$ : (a) as-polished surface, (b) after $1 \mathrm{~h}$, and (c) after $92 \mathrm{~h}$. The labels 1, 2 and 3 mark different grains whose surface roughness is measured in Table 2. times; is listed in Table 2. For surface roughness terminology in SPM, the reader is referred to reference [15]. As-received grain 2 had the highest surface roughness, possibly due to different planar density on this particular orientation. After exposure to humid air $(92 \% \mathrm{RH}$, for $92 \mathrm{~h})$ magnesia crystallites were unequally affected because each had a different crystallographic orientation (Fig. 2). As indicated by surface roughness, some periclase grains showed a higher tendency to hydrate than others. It is noted that the grain labeled 3 was the most impacted by humidity, possessing the roughest surface after $92 \mathrm{~h}$. As can be seen from Fig. 3c, all grains were coated

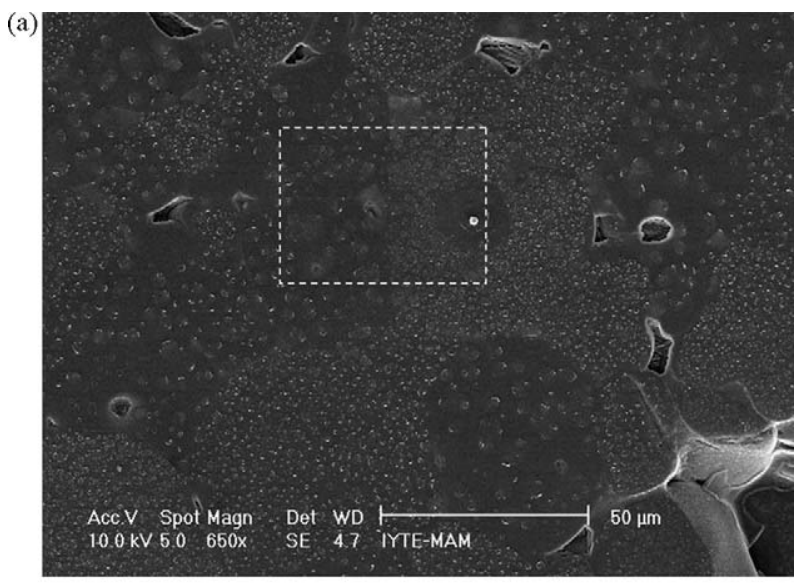

(b)

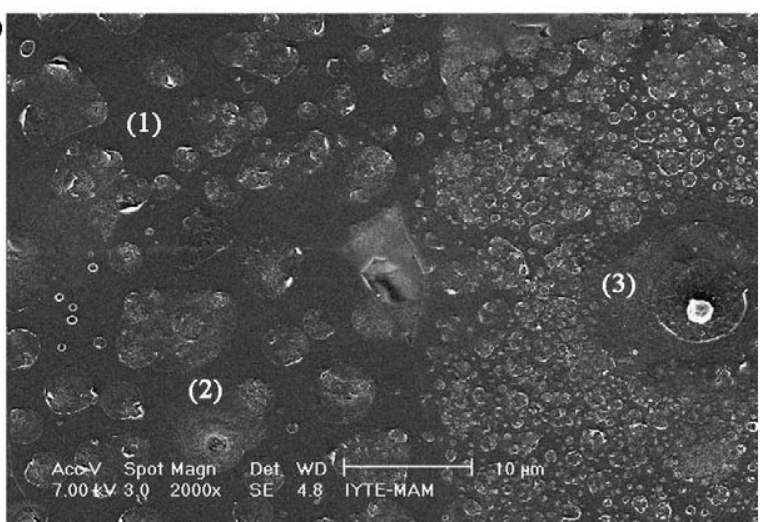

Fig. 4. (a) The SEM image of different magnesia refractory surface after $92 \mathrm{~h}$ at $92 \% \mathrm{RH}$ at $26^{\circ} \mathrm{C}$ and (b) closed-up view of the triple grain junction area marked by a square above. 
Table 2

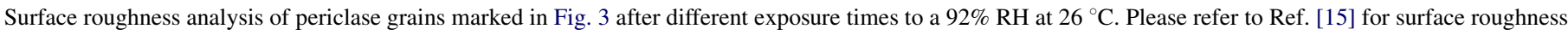
terminology used in describing SPM images.

\begin{tabular}{|c|c|c|c|c|c|c|c|c|c|c|}
\hline & Humidity exposure time & Polishe & irface & & $1 \mathrm{~h}$ & & & $92 \mathrm{~h}$ & & \\
\hline \multirow{9}{*}{$\begin{array}{l}\text { Surface roughness } \\
\text { analysis }(\mathrm{nm})\end{array}$} & Grain code number & (1) & (2) & (3) & (1) & (2) & (3) & (1) & (2) & (3) \\
\hline & Grain orientation & $\left(\begin{array}{lll}1 & 0 & 3\end{array}\right)$ & $\left(\begin{array}{lll}0 & 0 & 1\end{array}\right)$ & $\left(\begin{array}{lll}1 & 0 & 1\end{array}\right)$ & $\left(\begin{array}{lll}1 & 0 & 3\end{array}\right)$ & $\left(\begin{array}{lll}0 & 0 & 1\end{array}\right)$ & $\left(\begin{array}{lll}1 & 0 & 1\end{array}\right)$ & $\left(\begin{array}{lll}1 & 0 & 3\end{array}\right)$ & $\left(\begin{array}{lll}0 & 0 & 1\end{array}\right)$ & $\left(\begin{array}{lll}1 & 0 & 1\end{array}\right)$ \\
\hline & Amount of sampling & 3055 & 3087 & 3055 & 5103 & 6572 & 5184 & 5148 & 7372 & 8742 \\
\hline & Maximum (nm) & 923.9 & 1259.5 & 1142.7 & 949.4 & 1311.4 & 1188.7 & 1132.4 & 1501.5 & 1835.0 \\
\hline & Minimum (nm) & 761.2 & 1050.3 & 1034.2 & 755.9 & 973.9 & 1043.9 & 875.7 & 1020.9 & 1104.1 \\
\hline & Peak-to-peak, Ry (nm) & 162.8 & 209.2 & 108.5 & 193.4 & 337.4 & 144.7 & 256.6 & 480.6 & 730.9 \\
\hline & Average height (nm) & 850.6 & 1150.5 & 1085.3 & 867.2 & 1148.9 & 1107.8 & 961.4 & 1204.8 & 1502.4 \\
\hline & Average roughness, $\mathrm{Ra}(\mathrm{nm})$ & 28.5 & 37.6 & 19.8 & 33.3 & 56.0 & 22.1 & 50.6 & 100.9 & 106.2 \\
\hline & Root mean square, $\mathrm{Rq}(\mathrm{nm})$ & 34.7 & 45.3 & 23.5 & 40.9 & 68.3 & 27.5 & 58.5 & 115.2 & 129.4 \\
\hline
\end{tabular}

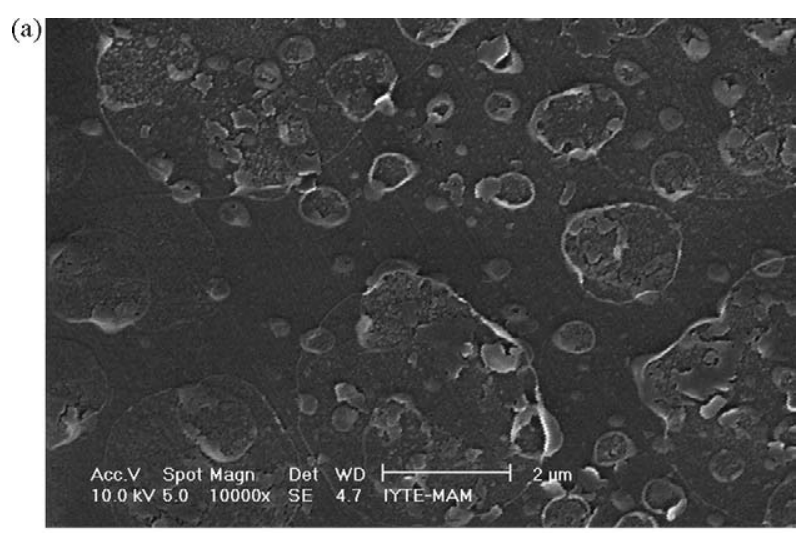

(b)

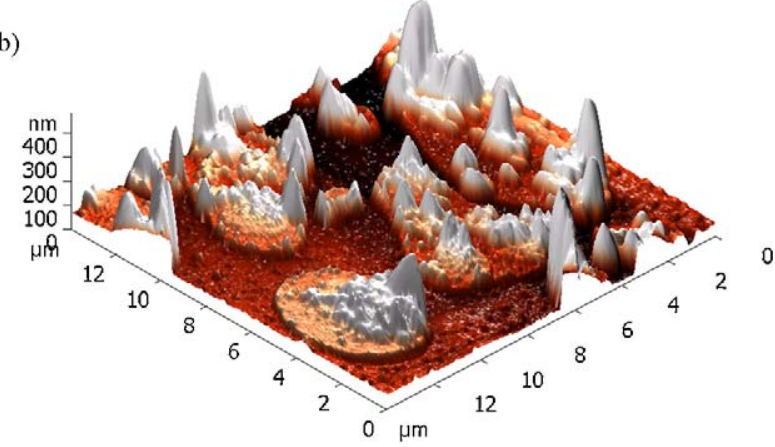

(c)

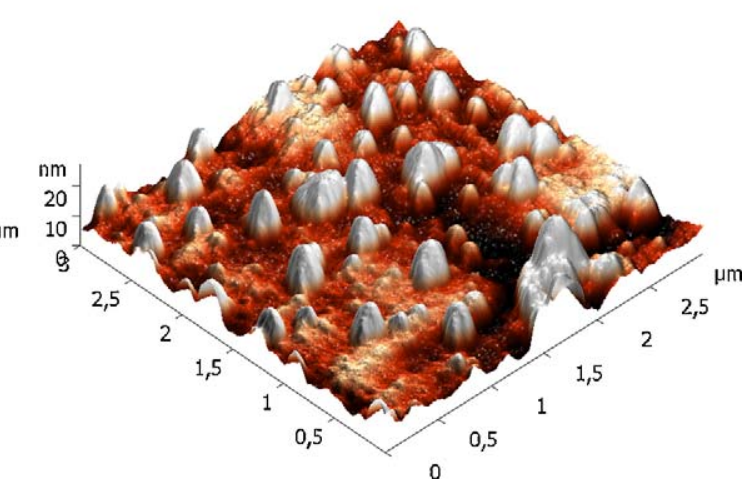

Fig. 5. (a) The SEM image of the hydrated surface after $92 \mathrm{~h}$ and SPM images of magnesium hydroxide clusters in a grain after (b) $92 \mathrm{~h}$ and (c) $1 \mathrm{~h}$ of exposure at $92 \% \mathrm{RH}$ at $26^{\circ} \mathrm{C}$. with a hydroxide layer; with increases in average height of the grain surfaces of grains 1,2 and 3, being $111 \mathrm{~nm}, 54 \mathrm{~nm}$ and $417 \mathrm{~nm}$ at $92 \% \mathrm{RH}$ after $92 \mathrm{~h}$, respectively.

In a previous study [7], it was shown using SPM and SEM that crystallographic orientation has an important influence on hydration degree of the $\mathrm{MgO}$, and that the (1 111 )-oriented $\mathrm{MgO}$ surface is more sensitive to humid atmosphere than the others. Refson et al. showed that water molecules physisorb readily on the perfect $\mathrm{MgO}\left(\begin{array}{lll}0 & 0 & 1\end{array}\right)$ surface, while dissociative chemisorption of water (placing $\mathrm{OH}^{-}$group above the $\mathrm{Mg}$ ion and $\mathrm{H}^{+}$above the surface oxygen) is energetically favored at lowcoordinated surface defect sites only [5]. Therefore, surface hydroxyl groups cause surface growths in the form of protrusions consisting of poorly ordered hydroxide. This is thought to be because the presence of $\mathrm{H}^{+}$on the surface of $\mathrm{MgO}\left(\begin{array}{lll}1 & 1 & 1\end{array}\right)$ creates a surface with the same structure as the $\mathrm{Mg}(\mathrm{OH})_{2}\left(\begin{array}{llll}0 & 0 & 0 & 1\end{array}\right)$ cleavage plane, and that this structure may stabilize the $\mathrm{MgO}\left(\begin{array}{lll}1 & 1 & 1\end{array}\right)$ surface [5]. It is known that $\mathrm{MgO}$ has a higher tendency to hydrate when the atoms on the plane have a coordination number of 3 , and a lower tendency to hydrate for a coordination number of 5 [6].

In this study, the most affected grains based on visual appearance and surface texture measurements tended to be the (1 0 1)-oriented $\mathrm{MgO}$ grains (Fig. 3c). The effect of crystallographic orientation on periclase hydration is clearly shown in the SPM image of Fig. 3 and SEM image of Fig. 4. Surface hydration rates of these three grains shown in Fig. 1 are calculated from Table 2 and are given in Table 3. These values were calculated using the average height from the as-received sample's polished surface. The results indicated that the $\left(\begin{array}{lll}0 & 0 & 1\end{array}\right)$ grain hydrated at a rate of $0.59 \mathrm{~nm} / \mathrm{h}$, while the $\left(\begin{array}{lll}1 & 0 & 1\end{array}\right)$ grain hydrated at $4.53 \mathrm{~nm} / \mathrm{h}$. Because this was a randomly selected area on the specimen, a grain oriented at $\left(\begin{array}{lll}1 & 1 & 1\end{array}\right)$ could not be found. These hydration rates were compared in Table 3 with

Table 3

Hydration rates $(\mathrm{nm} / \mathrm{h})$ of the marked grains calculated according to average height from Table 2.

\begin{tabular}{lll}
\hline Grain orientation & Previous study [7] & This study \\
\hline$\left(\begin{array}{lll}0 & 0 & 1\end{array}\right)$ & 0.57 & 0.59 \\
$\left(\begin{array}{lll}1 & 0 & 1\end{array}\right)$ & 1.33 & 4.53 \\
$\left(\begin{array}{lll}1 & 1 & 1\end{array}\right)$ & 3.91 & Not available \\
$\left(\begin{array}{lll}1 & 0 & 3\end{array}\right)$ & Not available & 1.20 \\
\hline
\end{tabular}


those obtained from a previous study that involved single crystals of the same orientation [7]. It was noted that the hydration rate for polycrystalline refractory specimen showed higher rate of hydration than single crystal specimens. This increase in hydration could be attributed to the effect of impurities in the commercial refractory specimen, although other factors may influence it.

Fig. 5 shows the SEM and SPM images of magnesium hydroxide clusters on samples treated with $92 \%$ humidity for $92 \mathrm{~h}$ at $26{ }^{\circ} \mathrm{C}$. After initiation of hydration, small magnesium hydroxide clusters started to grow, with their sizes increasing with time. Water tends to condense on the $\mathrm{MgO}$ surface in the form of spheres, which forms the clusters of hydrated areas observed in the image. When small hydroxide clusters were very near each other, they tended to coalesce into a larger cluster. Circular shapes of the clusters and their isolated positions suggest that the wetting angle between $\mathrm{MgO}$ and $\mathrm{H}_{2} \mathrm{O}$ was not low. Hydration was more pronounced inside the circular cluster compared to the rest of the specimen surface.

The rate of loss of refractory phases by hydration varied from 0.59 to $4.53 \mathrm{~nm} / \mathrm{h}$ under $92 \%$ humidity, depending on the crystal orientation of the three grains studied (Table 3 ). This much of material loss may be insignificant for a bulk brick, but can be a serious threat for a magnesia castable consisting of fine magnesia powder due to the large surface area exposed to humidity or water.

\section{Conclusions}

It was found that magnesia crystallites were significantly influenced by humidity at $26^{\circ} \mathrm{C}$. The crystallographic orientation of magnesia crystallites for the samples studied was found to affect the degree of hydration in a humid atmosphere. Large magnesium hydroxide clusters were formed on the surfaces of magnesia grains after hydration. After long time periods of exposure to moisture, it was observed that the magnesia polycrystalline grains were hydrated at a rate up to $4.53 \mathrm{~nm}$ of thickness per hour. It was found that $\mathrm{MgO}$ grains oriented at ( $\left.\begin{array}{lll}1 & 0 & 1\end{array}\right)$ were hydrated faster compared to $\left(\begin{array}{lll}0 & 0 & 1\end{array}\right)$ and (1 $\left.\begin{array}{lll}0 & 3\end{array}\right)$. This amount of material loss may be unimportant for a large brick, but can be a serious threat for a magnesia castable which consists of fine magnesia powder in contact with water. Intergranular bond phase of monticellite was less prone to hydration than the periclase grains.

\section{Acknowledgement}

The authors would like to thank the Center for Materials Research for their help in SEM analysis of the samples.

\section{References}

[1] W.E. Lee, R.E. Moore, Evolution of in situ refractories in the 20th century, Journal of the American Ceramic Society 81 (6) (1998) 1385-1410.

[2] J. White, Basic refractories: a survey of present knowledge, Proceedings of the Annual General Meeting of the Iron and Steel Institute, Refractories for Oxygen Steelmaking, Special Report 74, London, 1962.

[3] W. Zednicek, Periclase-A Remarkable and Essential Mineral for Refractory Ceramics, vol. 4, Radex-Rundschau, 1985 651-695.

[4] T.V. Chusovitina, A.F. Maurin, Effect of calcium oxide on the hydration activity of the powders of electrical-engineering periclase, Refractories and Industrial Ceramics 29 (7) (1988) 453-457.

[5] K. Refson, R.A. Wogelius, D.G. Fraser, M.C. Payne, M.H. Lee, V. Milman, Water chemisorption and reconstruction of the $\mathrm{MgO}$ surface, Physical Review B 52 (15) (1995) 10823-10826.

[6] J.H. Lee, J.H. Eun, S.G. Kim, S.Y. Park, M.J. Lee, H.J. Kim, Hydration behavior of $\mathrm{MgO}$ single crystals and thin films, Journal of Materials Research 18 (12) (2003) 2895-2903.

[7] M. Sutcu, S. Akkurt, S. Okur, Influence of crystallographic orientation on hydration of MgO single crystals, Ceramics International 35 (2009) 25712576.

[8] S. Akkurt, H.D. Leigh, Characterization of composite $\mathrm{MgO}-\mathrm{C}$ refractories as an initial step to understanding corrosion, Canadian Ceramics Quarterly-Journal of the Canadian Ceramic Society 71 (3) (2002) 9-18.

[9] S. Palco, M. Rigaud, T.T. Chen, D.H.H. Quon, B. Martin, H. LeDoussal, Characterization of the microstructure of refractory grade magnesia of different origins, Canadian Ceramics Quarterly-Journal of the Canadian Ceramic Society 62 (4) (1993) 253-257.

[10] W.E. Lee, M. Rainforth, Ceramic Microstructures: Property Control by Processing, Springer, New York, 1994.

[11] M.P. Delplancke-Ogletree, M. Ye, R.F. Winand, J. de Marneffe, R. Deltour, Influences of thermal annealing and humidity exposure on surface structure of $\left(\begin{array}{lll}1 & 0 & 0\end{array}\right)$ single-crystal $\mathrm{MgO}$ substrate, Journal of Materials Research 14 (5) (1999) 2133-2137.

[12] B. Heidberg, T. Bredow, K. Littmann, K. Jug, Ceramic hydration with expansion - the structure and reaction of water layers on magnesium oxide - a cyclic cluster study, Materials Science Poland 23 (2) (2005) 501-508.

[13] R. Salomão, L.R.M. Bittencourt, V.C. Pandolfelli, A novel approach for magnesia hydration assessment in refractory castables, Ceramics International 33 (2007) 803-810.

[14] W. Nesse, Introduction to Optical Mineralogy, Oxford University Press, Oxford, 1991.

[15] M. Raposo, Q. Ferreira, P.A. Riberio, A guide for atomic force microscopy analysis of soft-condensed matter, in: A. Méndez-Vilas (Ed.), Modern Research and Educational Topics in Microscopy, No. 3, vol. 1, FormatexMicroscopy Series, 2007, pp. 758-769. 